Türkiye Tarımsal Araştırmalar Dergisi
http://dergi.sirt.edu.tr $\begin{aligned} & \text { Turk J Agric Res } \\ & \text { (2015) 2: 118-122 } \\ & \text { TÜTAD } \\ & \text { ISSN: 2148-2306 }\end{aligned}$

\title{
Empis (Euempis) Frey, 1953 (Diptera:Empididae) Altcinsinden Türkiye Faunası için Yeni Bir Kayıt ve Ek Kayıtlar
}

\author{
Mustafa Cemal ÇíFTÇí \\ Siirt Üniversitesi, Ziraat Fakültesi, Bitki Koruma Bölümü, Siirt, TÜRKIYYE
}

\begin{abstract}
\begin{tabular}{ll}
\hline Geliş Tarihi/Received: 15.08 .2015 & Kabul Tarihi/Accepted: 23.09 .2015 \\
\hline
\end{tabular}
*Sorumlu Yazar/Correspondence: empididae@gmail.com

Özet: Bu çalışmada Empis spiralis Collin, 1937 Türkiye faunası için ilk kez kayıt edilmiștir. Ayrıca Türkiye ve Palaearktik bölgede oldukça geniş yayılış alanına sahip Empis tessellata Fabricius, 1794 Siirt ilinden, Empis pleurica (Collin, 1960) ve Empis dasycera (Collin, 1960) türleri ise Osmaniye ilinden ilk defa bildirilmektedir. Türkiye faunası için yeni kayıt ile Türkiye'deki Empis (Euempis) altcinsine ait tür sayısı 8'e, Empis cinsine ait tür sayısı ise 60'a yükselmiştir. Ayrıca Türkiye'den bilinen Empis (Euempis) türlerinin listesi ve bu türler için teşhis anahtarı (İngilizce ve Türkçe) verilmiştir.
\end{abstract}

Anahtar Kelimeler: Siirt, Osmaniye, Empis spiralis, fauna, Türkiye

\section{A New Record and Additional Records for Turkish Fauna from Subgenus Empis (Euempis) Frey, 1953 (Diptera:Empididae)}

\begin{abstract}
With this study, Empis spiralis Collin, 1937 recorded for the first time from Turkish fauna. Also in this study, Empis tessellata Fabricius, 1794 which has fairly wide distribution in the Turkey and Palaearctic Region is given for the first time from Siirt province. Empis pleurica (Collin, 1960) and Empis dasycera (Collin, 1960) recorded from Osmaniye are first records for province. With new record for Turkey, the species number of Empis (Euempis) has increased to 8 while genus Empis 60 from Turkey. A checklist of the subgenus Empis (Euempis) species of Turkey and an identification key (in Turkish and English) for Turkish Empis (Euempis) species are given.
\end{abstract}

Keywords: Siirt, Osmaniye, Empis spiralis, fauna, Turkey

\section{Giriș}

Empididae familyası türlerinin erginleri genellikle küçük ve orta boylu sinekler olup vücut uzunlukları 1.5-12 $\mathrm{mm}$ arasında değişmektedir. Vücut genellikle siyah, parlak ya da yoğun gri tozlu, bazı türlerde ise vücut tamamen sarı [Empis (Xanthempis) altcinsi ve bazı Hilara türleri] renklidir. Baş küçük, yuvarlak, bileşik gözler başın büyük bir kısmını kaplar. Ağız hortumu genellikle uzun ve arkaya doğru yönelmiş ve daha çok çiçek ziyaretçileri iken kısa hortumlu türler daha çok avcılık yaparak beslenirler (Chvála, 1983 ve 1994).
Empididae familyası çeşitli beslenme alışkanlıkları gösterirler. Bunlar içerisinde en yaygın olanları avcılık (yaşayan ya da ölü böcekler ile beslenir) ve çiçek ziyaretçiliğidir (çiçek öz sularıyla beslenirler). Çiçek ziyaretçisi teriminin kullanılmasındaki amaç erginlerin sadece nektarla ya da polenlerle beslenmemesi, bununla birlikte avcılıkta yapmalarıdır. Bununla anlaşılacağı gibi avcılık temel olanıdır ve en ilkel formlardan en özelleşmiş avc1 formların çoğu grupta görülmektedir (Chvála, 1983).

Beslenme alışkınlıkları en iyi çalışılmış altfamilya Empidinae (Empis, Rhamphomyia, 
Hilara cinsleri) alt familyasıdır. Genellikle bu altfamilyanın her iki eşeyi de çiftleşme dönemleri dışında çiçekleri ziyaret eder, fakat çiftleşme döneminde ise erkek çiftleşmeden önce böcek yakalar ve bunu evlilik hediyesi olarak ilk çiftleşme teması sırasında dişiye verir. Dişiler böcek avını kopulasyon sırasında yer, fakat erkeklerin kendi yakaladıkları avları yemesi hakkında hiçbir bilgi bulunmamaktadır (Chvála, 1983).

Empididler üreme dönemlerinde havada kümeler oluştururlar. Kümeleşmeler empididler için çok karakteristik olup, bu cinsel davranışları Empididae familyasının isimlerine de yansıyarak "dans sinekleri" denilmektedir. Uçuş tipi, kümedeki bireylerin sayısı ve kümenin büyüklüğü ve şekli birbirinden farklıdır ve türler kümeler oluşturma faaliyetleri sayesinde kolayca tanımlanabilir. (Chvála, 1983).

Empididler çiçek ziyaretçisi olduklarından dolayı bitkilerdeki tozlaşma açısından oldukça önemli olan böcekler arasında yer almaktadır. Vücutlarında bulunan yoğun kıllanma nedeniyle nektarla beslenme sirasında vücut yüzeylerinde büyük miktarda polen birikebilir ve bu polenleri diğer çiçeklere taşıyarak tozlaşmada önemli rol oynamaktadırlar (Collin, 1961; Chvála, 1983).

Empis (Euempis) altcinsi türleri diğer Empis türlerine kıyasla büyük ve iri türlerdir ve vücut uzunlukları 5-12 mm arasında olup yoğun kıllı ve uzun bristilli sineklerdir. Renklenmesi siyah olan bu türlerin vücutları üzerinde yoğun tozlanma nedeniyle tozlanmanın rengine göre grimsi-sarı ya da grimsi-kahverengi görünmektedirler. Hortumları (proboskis) kuvvetli yapıda olup, labrumları oldukça uzundur. Toraks üzeri yoğun kıllarla kaplı olan Empis (Euempis) türlerinin mesonotumları üzerinde yer alan genellikle 3 siyah bant belirgindir. Bacaklar siyah ya da siyahımsı kahverengi, ayrıca belirli kısımlarında (femur ve tibiaların uç kısımları gibi) yer yer sarımsı bölgeler bulunabilir. Bacaklar üzerindeki bristiller kalın ve bazıları diken şeklindedir. Abdomen üzerindeki kıllanma kisa ve yoğundur, erkeklerdeki arka kenar bristilleri belirgin, dişilerde ise bristiller sadece ilk tergitte bulunur. Büyük vücut yapıları, vücut ve bacak üzerinde sınırları belli olmayan kıllanma ve bristillenme ile çiftleşme sırasında dişiye av sunumunun olmaması bu altcinsin Empis cinsinin en ilkel altcinsi olarak görülmesine neden olmaktadır (Chvála, 1994).

Türkiye'deki Empididae familyasına ait çalışmalar son yıllarda başlamıştır. Son on yıl içerisinde yapılan çalışmalarla Türkiye faunası Empididae familyası tür sayısı hızlı bir artışın içerisine girmiştir. Empis cinsinin Türkiye'den bilinen tür sayısı 59'dur (Çiftçi ve Hasbenli, 2007a, 2007b, 2008 ve 2013; Çiftçi ve ark., 2012). Empis (Euempis) altcinsinden Avrupa'da 15 tür kaydedilmişken bu sayı Türkiye'de 7'dir (Çiftçi ve Hasbenli, 2007a ve 2013; Anonymous, 2015). Türkiye'de yayılış gösteren 4 tür Avrupa'da da yayılış gösterirken, geri kalan 3 tür Ortadoğu'da yayılış gösterir (Chvála ve Wagner, 1989; Çiftçi ve Hasbenli, 2007a ve 2013).

\section{Materyal ve Yöntem}

$\mathrm{Bu}$ çalışma 2014-2015 yılları arasında Siirt ve Osmaniye illerinden arazi çalışmaları sonucunda toplanan 25 (13 erkek, 12 dişi) empidid örneğini temel almaktadır. Çalışma alanında örnekler farklı bitki örtüsüne sahip habitatlardan atrap kullanılarak süpürme yöntemi ile toplanmıştır. Yakalanan örnekler etil asetatlı öldürme kavanozlarında öldürüldükten sonra aynı gün akşam zarflanmış ve lokalite bilgilerinin kayıt edilmiştir. Arazi çalışmalarından sonra müze ortamına getirilen örneklerden büyük olanlar böcek iğneleriyle iğnelenmiş, küçük örnekler küçük üçgen kâğıtlara yapıştırılmış sonrada lokalite bilgileri verilerek standart müze materyali haline getirildikten sonra koleksiyon kutularına yerleştirilmiştir.

Araziden toplanan örneklerin teşhisleri sırasında dış morfolojik özelliklerinin yanı sıra erkek genitali de kullanılmıştır. Genital peparatları yapılacak örneğin abdomeni stereo-mikroskop altında bisturi yardımıyla dikkatle kesilmiştir. Kesilen abdomen \% 5'lik $\mathrm{KOH}$ (potasyum hidroksit) çözeltisine alınıp oda sıcaklığında yaklaşık 24 saat bekletilmiș ve sonrasında su ile yıkanmıştır. Yıkanan genital suyunun alınabilmesi için \% 70'lik etil alkol içerisine alınarak birkaç saat bekletilmiştir. Daha sonra çukur lam içinde gliserin ortamında geçici preparat haline getirilerek stereo-mikroskop yardımıyla teşhisler yapılmıştır. Genital parçaları incelendikten sonra örneğin lokalite numarası ve buna ek olarak genital numarası da verilerek küçük plastik tüplerde (bim kapsülü) gliserin içinde, ait olduğu örneğin yanına iğnelenerek muhafaza edilmiştir.

Örneklerin teşhisinde Chvála (1994), Collin (1937, 1960) çalışmalarından yararlanılmıştır. Arazi çalışmaları sonrasında tespit edilen türlerin ve Türkiye'deki ve Palaearktik bölgedeki diğer Empis (Euempis) altcisine ait türlerin yayılışları verilirken Chvála ve Wagner (1989) ve Çiftçi ve Hasbenli (2007a, 2013) çalışmalarından yararlanılmıştır.

Teşhisi yapılan ve tasnif kutularına yerleştirilen Empididae örnekleri yazarın özel koleksiyonunda saklanmaktadir. 


\section{Bulgular}

\subsection{Empis dasycera (Collin, 1960)}

Incelenen Materyal: 1亏ิ, 1 ,, Osmaniye, Düziçi, Harun Reşit Kalesi, $37^{\circ} 16^{\prime} 02^{\prime \prime} \mathrm{K}$ $36^{\circ} 29^{\prime} 11 " \mathrm{D}, 710 \mathrm{~m}, 26.04 .2015$.

Palaearktik yayılış: İsrail, Ürdün, Türkiye

(Collin, 1960; Chvála ve Wagner, 1989; Çiftçi ve Hasbenli, 2007a).

\subsection{Empis pleurica (Collin, 1960)}

Incelenen Materyal: $3 \widehat{\widehat{\partial}}$, Osmaniye, Düziçi, Harun Reşit Kalesi, 37¹6'02"K 36²9'11"D, 710 m, 26.04.2015; 1§, 2qㅇ, Osmaniye, Düziçi, Karatepe-Aslantaş Milli Parkı, 37²17'23"K 36²16'12"D, $211 \mathrm{~m}, 26.04 .2015$.

Palaearktik yayılış: Filistin, Ürdün, Türkiye (Collin, 1960; Chvála ve Wagner, 1989; Çiftçi ve Hasbenli, 2013).

\subsection{Empis spiralis Collin, 1937}

Incelenen Materyal: $6 \partial^{\lambda} \partial^{\lambda}, 8 ㅇ ㅗ$, Siirt, Merkez, Köprübaş1 köyü, 3757'49"K41 $51^{\circ} 35^{\prime}$ "D, 545 m, 12.04.2014.

Palaearktik yayılış: Kıbrıs, Cezayir, İran, İsrail, Suriye, Ürdün (Chvála ve Wagner, 1989; Shamshev ve Grootaert, 2005). Bu tür Türkiye için yeni kayittır.

\subsection{Empis tessellata Fabricius, 1794}

Incelenen Materyal: 10, Siirt, Merkez, Köprübaş1 köyü, 3757'49"K 41ํํ'35"D, 545 m, 10.05.2015; 1ठ, Siirt, Merkez, Yerlibahçe köyü,

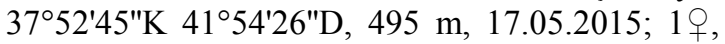
Siirt, Merkez, Yazlıca köyü, 3742'49"K 41ํ9'25"D, $458 \mathrm{~m}, 17.05 .2015$.

Palaearktik yayılış: Tüm Palaerktik bölgede yayılış göstermektedir (Chvála ve Wagner, 1989).

\section{Tartıșma ve Sonuçlar}

Empis (Euempis) altcinsi Empis cinsinin en ilkel formlarını oluşturmaktadır. Avrupa'da Empis (Euempis) altcinsinden 15 tür biliniyorken Türkiye'de 7 tür ile temsil edilmekteydi. Türkiye'deki türlerden 4'ü Avrupa'da da yayılış göstermektedir. Bunlar Empis calcarata, E. kerteszi, E. tessellata ve E. sericans'tır (Anonymous, 2015).

Empis dasycera ve E. pleurica türleri Avrupa'da yayılış göstermezler. Bu türler sadece Ortadoğu bölgesinde bulunurken yayılış alanları oldukça küçük bir bölgeyi kapsamaktadır. E. shushaensis türü ise Kafkas yayılışlı bir türdür ve sadece bu bölgeden bilinmektedir.

Bu çalışmada ilk kez kaydedilen Empis spiralis türü de E. dasycera ve E. pleurica türleri gibi
Ortadoğu yayılışlıdır, fakat Avrupa kıtasında sayılan Kıbrıs adasından da kaydı bulunduğu için Avrupa'da yayılış gösterdiği söylenmektedir. Bu üç türün genel yayılışına bakıldığında ise Doğu Akdeniz alt bölgesi kökenli olduğu söylenebilir.

Empis (Euempis) altcinsi türlerinin Türkiye'deki yayılışlarına bakıldığında türlerin Palaearktik bölgedeki yayılışlarına uygun bir dağılıma sahip olduğu söylenebilir. Örnek olarak E. shushaensis türü Kafkas kökenlidir ve Türkiye'de Artvin'den bilinmektedir, E. spiralis Ortadoğu kökenli olup bu çalışma ile Türkiye'den sadece Siirt ilinden kaydedilmiştir. E. kerteszi Avrupa kökenli bir türdür ve Türkiye'den de sadece Trakya'dan bilindiği için bu türün Ortadoğu ya da Asya kıtasında yayılışı bulunmamaktadır.

Empis dasycera ve E. pleurica türleri Ortadoğu yayılışlı olup, Türkiye'de de daha çok güney illerimizden bilinmektedir, fakat E. pleurica türünün Çanakkale'den kayıtlı olması bu türün Avrupa'da da yayılış gösterebileceğinin göstergesidir. Ayrıca bu türlerin Türkiye'deki yayılışlarının en doğu sınırı Osmaniye olarak bu çalışmayla genişlemiştir.

Empis calcarata, E. sericans ve E. tessellata türleri kısmen de olsa Türkiye'de diğer türlerden daha fazla yayılış alanına sahiptir. E. tessellata türünün Palaearktik bölgede yaygın olarak bulunması Türkiye'deki geniş yayılışa sahip olmasını açıklamaktadır. E. tessellata türü Türkiye'nin orta ve batı bölgelerinde yayılış gösterir ve bu çalışmada verilen Siirt kaydı ile yayılış sınırı Türkiye'nin güneydoğu kısmına kadar genişlemiştir. E. sericans da E. tessellata gibi orta ve batı bölgelerde yayılış göstersede Gümüşhane'den kaydının olması bize bu türün Türkiye'nin kuzey ve kuzeydoğusunda da yayılışı olduğunu göstermektedir. E. calcarata'nın yayılışına bakıldığında $E$. tessellata'nın yayılış alanlarıyla kesiştiği görülmektedir. Bu türde daha çok Türkiye'nin orta ve batı kesimlerinde bulunmaktadır.

Yapılan bu çalışma ile Empis spiralis türü Türkiye'den ilk kez kayıt edilerek Türkiye'deki Empis (Euempis) altcinsi tür sayısı 7'den 8'e, Türkiye'den bilinen Empis cinsi tür sayısı ise 59'dan 60'a yükselmiştir. E. spiralis' in Palaearktik bölgedeki yayılış alanı bu çalışmayla birlikte Türkiye'yi de kapsayarak (Siirt) genişlemiştir. Yine bu çalışma ile E. tessellata türü Siirt ilinden, E. pleurica ve E. dasycera türleri ise Osmaniye ilinden ilk kayıtları verilmiştir. Yapılacak daha kapsamlı çalışmalarla Türkiye'deki Empis (Euempis) altcinsi tür sayının artması ve tür yayılışlarının genişlemesi beklenmektedir. 
Türkiye Empis (Euempis) türlerinin listesi: $\mathrm{Bu}$ tür listesinde, Türkiye'de dağılış gösteren Empis (Euempis) altcinsinin tür isimleri ve varsa sinonimleri verilmiştir. Tür isimleri alfabetik olarak dizilmiştir. Literatür sütununda ilgili türlerin Türkiye'deki yayılış bilgilerini veren çalışmalar yazılmıştır (Tablo 1).

Tablo 1. Türkiye'de yayılış gösteren Empis (Euempis) altcinsi türlerinin listesi

\begin{tabular}{|c|c|c|}
\hline Tür Ad1 & Yayılış & Literatür \\
\hline calcarata Bezzi, 1899 & $\begin{array}{l}\text { Antalya, Hatay, Isparta, Kayseri, } \\
\text { Konya, Kocaeli, Mersin, Niğde, } \\
\text { Yozgat, Zonguldak }\end{array}$ & Çiftçi ve Hasbenli (2007a) \\
\hline dasycera (Collin, 1960) & $\begin{array}{l}\text { Adana, Isparta, Kayseri, Konya, } \\
\text { Osmaniye }\end{array}$ & $\begin{array}{l}\text { Çiftçi ve Hasbenli (2007a); Mevcut } \\
\text { yayın }\end{array}$ \\
\hline kerteszi Bezzi, 1900 & Kırklareli, Edirne & Çiftçi ve Hasbenli (2013) \\
\hline pleurica (Collin, 1960) & $\begin{array}{l}\text { Çanakkale, Konya, Isparta, } \\
\text { Mersin, Niğde, Osmaniye }\end{array}$ & $\begin{array}{l}\text { Çiftçi ve Hasbenli (2013); Mevcut } \\
\text { yayın }\end{array}$ \\
\hline $\begin{array}{l}\text { sericans Brullé, } 1832 \\
=\text { nepticula } \text { Loew, } 1869\end{array}$ & $\begin{array}{l}\text { Adana, Balıkesir, Bartın, Bilecik, } \\
\text { Bursa, Çanakkale, Çankırı, } \\
\text { Edirne, Gümüşhane, Karabük, } \\
\text { Kocaeli, İstanbul }\end{array}$ & Çiftçi ve Hasbenli (2013) \\
\hline shushaensis Shamshev, 2001 & Artvin & Çiftçi ve Hasbenli (2007a) \\
\hline spiralis Collin, 1937 & Siirt & Mevcut yayin \\
\hline $\begin{array}{l}\text { tessellata } \text { Fabricius, } 1794 \\
=\text { fraterna } \text { Loew, } 1865 \\
=\text { nigripes } \text { Strobl, } 1880 \\
=\text { tipuloides } \text { Strobl, } 1893 \\
=\text { genuina } \text { Strobl, } 1893 \\
=\text { atripes } \text { Strobl, } 1893\end{array}$ & $\begin{array}{l}\text { Adana, Amasya, Antalya, Bilecik, } \\
\text { Çanakkale, Edirne, Karabük, } \\
\text { Kayseri, Kocaeli, Konya, Mersin, } \\
\text { Sakarya, Yozgat }\end{array}$ & Çiftçi ve Hasbenli (2013) \\
\hline
\end{tabular}

Türkiye'de yayılış gösteren Empis (Euempis) altcinsi tür teşhis anahtarl:

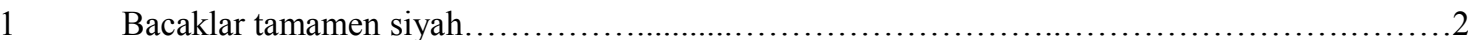

- $\quad$ Bacaklar tamamen siyah değil, femur ve tibialarda sarı, kahverengi bölgeler bulunur.................4

2 Büyük türler, vücut uzunluğu en az $8 \mathrm{~mm}$, akrostikal ve dorsosentral bristiller 3 ve daha çok siralı....................................................................................... Küçük tür, vücut uzunluğu en fazla $6 \mathrm{~mm}$, akrostikal ve dorsosentral bristiller 2 siralı..............................................................Empis spiralis Collin

3 Arka tibianın kaide kısmına doğru çıkıntı bulunur, aedeagus kalın kısa, dorsal lamel büyük ve aedeagusu örter................................................Empis shushaensis Shamshev Arka tibia üzerinde çıkıntı bulunmaz, aedeagus uzun ve ince, dorsal lamel aedeagusun sadece uç k1smını örter..............................................................Empis sericans Brullé

$4 \quad$ Metapleural bristiller sar1. Empis kerteszi Bezzi

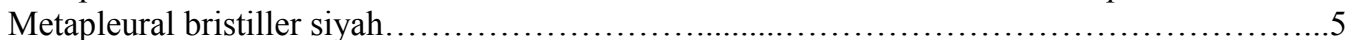

5 Büyük tür, vücut uzunluğu en az $9 \mathrm{~mm}$, erkeklerde 4. tergitin yan arka kenarlarında küme şeklinde bristil bulunmaz.........................................Empis tessellata Fabricius Küçük türlerdir, vücut uzunluğu en fazla 8 mm, erkeklerde 4. tergitin yan arka kenarlarında uzun küme şeklinde bristiller bulunur.

$6 \quad$ Akrostikal ve dorsosentral bristiller 2 siralı..................................Empis calcarata Bezzi Akrostikal ve dorsosentral bristiller 3 ve daha çok siralı........................................

$7 \quad$ Akrostikal bristiller toraksın arka kenarına kadar gider, 4 notopleural bristilli, erkeklerde 4. tergitin yan arka kenarı arkaya doğru çıkıntı yapmıştır.. Empis dasycera (Collin) Akrostikal bristiller toraksın arka kenarına kadar gitmez, 3 notopleural bristilli, erkeklerde 4. tergitin yan arka kenarı arkaya doğru çıkıntı yapmaz. ..Empis pleurica (Collin)

\section{Key to Turkish species of the Empis (Euempis):}

1 Legs completely black.

Legs not completely black, femur and tibia with yellowish and brownish parts 
Larger, body at least $8 \mathrm{~mm}$, acrostichal and dorsocentral bristles 3 or more serial................. Smaller, body at most $6 \mathrm{~mm}$, acrostichal and dorsocentral bristles 2

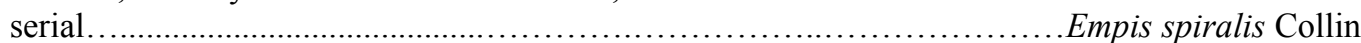
Hind tibia with apophysis, aedeagus short and stout, concealed within lamellae......................................................Empis shushaensis Shamshev Hind tibia without apophysis, aedeagus long and thin, mostly visible.........Empis sericans Brullé Metapleural fan yellow. Empis kerteszi Bezzi Metapleural fan black. Larger, body at least $9 \mathrm{~mm}$, tergum 4 in male simple.

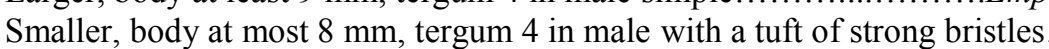
Eis tessellata Fabricius Acrostichal and dorsocentral bristles 2 serial. .Empis calcarata Bezzi

Acrostichal and dorsocentral bristles 3 or more serial. ... 7 Acrostichal bristles continued to hind margin of thorax, notopleura with 4 bristles, tergum 4 in male with a process on each side. Empis dasycera (Collin) Acrostichal bristles does not reach to hind margin of thorax, notopleura with 3 bristles, tergum 4 in male with a shining patch on each side.... ..Empis pleurica (Collin)

\section{Teşekkür}

$\mathrm{Bu}$ çalışma, Siirt Üniversitesi Bilimsel Araştırma Projeleri Koordinatörlüğü (BAP, 2015-SİÜZİR04) tarafından desteklenmiştir. Çalışmanın yürütülmesinde sağladıkları katkılardan dolayı BAP'a teşekkür ederiz.

\section{Kaynaklar}

Anonymous, 2015. Fauna Europaea, Version 2.6.2. http://www.faunaeur.org/ (Last update: 29.08.2013).

Chvála, M., 1983. The Empidoidea (Diptera) of Fennoscandia and Denmark. II. General Part. The Families Hybotidae, Atelestidae and Microphoridae, Vol 12. Fauna Entomologica Scandinavica, Leiden, New York, Köln.

Chvála, M., 1994. The Empidoidea (Diptera) of Fennoscandia and Denmark. III Genus Empis, Vol 29. Fauna Entomologica Scandinavica, Leiden, New York, Köln.

Chvála, M., Wagner, R., 1989. Family TherevidaeEmpididae, 228-337. In: Catalogue of Palaearctic Diptera, Vol: 6 (Ed: Soós, Á. \& Papp, L), Akadémiai Kiadó, Budapest.

Collin, J.E., 1937. Some Empididae (Diptera) from Syria and Asia Minor, Part 1. Proceedings of the Royal Entomological Society of London, (B), 6(8): 135144.
Collin, J.E., 1960. Some Empididae from Palestine. Annals and Magazine of Natural History, 13(2): 385-420.

Collin, J.E., 1961. British Flies, Empididae, 6. Cambridge, London.

Çiftçi, M.C., Hasbenli, A., 2007a. Contribution to Empis (subgenera Euempis, Pachymeria, Polyblepharis) (Empididae, Diptera) fauna of Turkey. Journal of the Entomological Research Society, 8(3): 7-14.

Çiftçi, M.C., Hasbenli, A., 2007b. Contribution to Empis (Subgenera Leptempis, Xanthempis and Lissempis) (Empididae, Diptera) Fauna of Turkey. $A n$ International Journal of Dipterological Research, 18(3): 154-157.

Çiftçi, M.C., Hasbenli, A., 2008. Contribution to Empis (Subgenus Empis) (Empididae, Diptera) Fauna of Turkey. Turkish Journal of Zoology, 32: 433-435.

Çiftçi, M.C., Hasbenli, A., 2013. New distributional data for the genera Empis Linnaeus and Rhamphomyia Meigen (Diptera: Empididae) in the Marmara Region with new records from Turkey. Turkish Journal of Zoology, 37: 582-593.

Çiftçi, M.C., Hasbenli, A., Canpolat, D., 2012. Two new species of Empis (Diptera: Empididae) from Turkey. Zootaxa, 3408: 47-53.

Shamshev, I.V., Grootaert, P., 2005. New data on the genus Empis Linnaeus (Diptera: Empididae) from Iran, with descriptions of two new species. Studia Dipterologica, 12(1): 29-36. 